\title{
UK military doctors; stigma, mental health and help-seeking: a comparative cohort study
}

\author{
Norman Jones, ${ }^{1}$ D Whybrow, ${ }^{2}$ R Coetzee ${ }^{3}$
}

${ }^{1}$ Academic Department of Military Mental Health, Ministry of Defence, Weston Education Centre, London, UK

${ }^{2}$ School of Healthcare Sciences, Cardiff University, Cardiff, UK ${ }^{3} \mathrm{HQ}$ Defence Primary Healthcare, Ministry of Defence, Lichfield, UK

Correspondence to Norman Jones, Ministry of Defence, Academic Department for Military Mental Health, Weston Education Centre, London, SE5 9RJ, UK; norman. jones@kcl.ac.uk

Received 30 January 2018 Revised 2 February 2018 Accepted 7 February 2018 Published Online First 9 March 2018
Check for updates

To cite: Jones N, Whybrow D, Coetzee R.

J R Army Med Corps 2018;164:259-266.

\section{ABSTRACT}

Introduction Studies suggest that medical doctors can suffer from substantial levels of mental ill-health. Little is known about military doctors' mental health and wellbeing; we therefore assessed attitudes to mental health, self-stigma, psychological distress and help-seeking among UK Armed Forces doctors.

Methods Six hundred and seventy-eight military doctors (response rate 59\%) completed an anonymous online survey. Comparisons were made with serving and ex-military personnel ( $n=1448$, response rate $84.5 \%$ ) participating in a mental health-related help-seeking survey. Basic sociodemographic data were gathered, and participants completed measures of mental health-related stigmatisation, perceived barriers to care and the 12-Item General Health Questionnaire. All participants were asked if in the last threeyears they had experienced stress, emotional, mental health, alcohol, family or relationship problems, and whether they had sought help from formal sources.

Results Military doctors reported fewer mental disorder symptoms than the comparison groups. They endorsed higher levels of stigmatising beliefs, negative attitudes to mental healthcare, desire to self-manage and self-stigmatisation than each of the comparison groups. They were most concerned about potential negative effects of and peer perceptions about receiving a mental disorder diagnosis. Military doctors reporting historical and current relationship, and alcohol or mental health problems were significantly and substantially less likely to seek help than the comparison groups.

Conclusions Although there are a number of study limitations, outcomes suggest that UK military doctors report lower levels of mental disorder symptoms, higher levels of stigmatising beliefs and a lower propensity to seek formal support than other military reference groups.

\section{INTRODUCTION}

Mental illness can be viewed in stigmatising or stereotypical ways; it can be viewed as socially unacceptable and such views can impact care pathways. ${ }^{1}$ A systematic review of military stigma research concluded that stigmatised military personnel are unwilling to access mental healthcare and that military personnel often self-stigmatise when they are psychologically distressed. ${ }^{2}$ A multinational study compared stigma across international armed forces and found stigma to be ubiquitous and associated with reduced help-seeking ${ }^{3}$; the authors suggested that increasing mental disorder symptom levels were associated with more self-stigmatising beliefs and reduced help-seeking from mental health support services; stigma was a more important determinant

\section{Key messages}

Little is known about mental health, stigma and help-seeking behaviours in military medical practitioners.

- Military doctors report lower levels of mental disorder symptoms and higher levels of stigmatising beliefs.

- Military doctors have a lower propensity to seek formal support when mentally unwell.

- Military doctors may require a bespoke mental health referral and treatment system in order to overcome barriers to care.

of help-seeking than practical barriers to care. Britt et $a l^{4}$ surveyed US military personnel and identified a significant relationship between mental health-related stigmatisation and mental distress. Practical barriers to care rather than self-stigmatising beliefs were strongly associated with reduced helpseeking. The evidence that stigma inhibits helpseeking is therefore somewhat unclear and is mostly derived from cross-sectional studies. Nonetheless, researchers frequently emphasise the importance of stigma in military populations and the potential negative impact on help-seeking. ${ }^{5}$ Mental ill-health stigmatisation is not limited to military contexts; a comparison of attitudes to mental health in UK civilian and military populations suggested that stigmatisation was often similar in form and content, although military respondents were less positive about mentally ill people being integrated into the workplace. ${ }^{6}$

Turning to doctors as a discrete occupational group, there is some evidence that self-stigmatising beliefs about seeking care are relatively common among doctors ${ }^{7}$ and that mental health-related stigma has a high prevalence even at the early stage of medical studentship ${ }^{8}$; links have been proposed between infrequent help-seeking and poorer health in civilian doctors. ${ }^{9}$ Doctors may not seek medical help for fear of letting either themselves, their patients or their colleagues down. ${ }^{10}$ Within the UK Armed Forces, military doctors occupy a unique position and are highly visible in a military unit. In these circumstances, there is a risk that any mental distress and associated help-seeking might be observed by peers and unit members, including commanders; research in civilian contexts suggests that doctors often attempt to conceal health problems by self-medicating in order to avoid disclosure to other doctors. ${ }^{11}$ To the best of our knowledge, attitudes to mental health disorders, stigmatising 
beliefs, symptoms of psychological distress and mental health-related help-seeking have not been studied in UK military doctors. Given the paucity of research in this area, this cross-sectional study sought to answer four questions:

Do military doctors:

1. report greater mental health-related stigmatisation, self-stigmatisation and perceived barriers to care than serving regular, reserve and military veteran groups?

2. who report symptoms of common mental disorder (CMD) or subjective health and well-being problems report more stigmatisation and perceived barriers to care than other military groups with similar problems?

3. seek formal help at greater or lesser levels than other military groups?

4. have different patterns of mental health stigmatisation than other military groups?

\section{METHODS}

Samples

Sample 1

Military doctors were invited to complete an anonymous online survey. A limited set of sociodemographic characteristics were gathered, including categorised rank groups, professional status (unaccredited or accredited practitioner), area of work (primary or secondary care), categorised service length, service background and sex.

\section{Sample 2}

The comparison sample comprised a subsample of military and ex-military reserve and regular engagement individuals participating in the third phase of a self-report health and well-being cohort study $(\mathrm{n}=7955) .{ }^{12}{ }^{13}$ Respondents in the main cohort study who endorsed having experienced a stress, emotional or mental health problem in the past threeyears $(n=1448)$ were invited to take part in a telephone interview, which included a number of questions and measures replicated in the doctor survey. Only the sex and rank variables were common to both data sets.

\section{Procedures}

Military doctors were recruited through multiple routes to complete the survey. Strategies included the provision of non-coercive email prompts from career managers, service heads, the UK Defence Medical Deanery and heads of individual medical specialties. Participants were directed to an online site where they were presented with an electronic survey, a participant information sheet and consent form; progressing to the survey indicated consent to participate. The survey took place between February and May 2017.

\section{Measures}

The doctor online survey and the comparison telephone interview survey contained measures of mental health-related stigmatisation and perceived barriers to care; these were assessed using a multiple response scale widely used in $\mathrm{UK}^{14}$ and US mental health research. ${ }^{15}$ Items from the Barriers to Access Care Evaluation scale ${ }^{16}$ and the Self-Stigma of Seeking Psychological Help Scale ${ }^{17}$ were used to assemble a composite stigma measure. All scale items were responded to using a five-item Likert scale; potential responses ranged from strongly disagree, disagree, neither agree nor disagree, agree and strongly agree. A binary variable was created for each individual mental health stigmatisation and practical care barrier item, which indicated endorsement (agree or strongly agree) and non-endorsement (two categories of disagreement plus the neither agree nor disagree response). Two scales were generated; stigma, which comprised stigmatisation, practical barriers to care and attitudes to mental healthcare (including a desire to self-manage); and a discrete self-stigmatisation scale. Each of the two scales were independently summed, tertiles were generated for each count variable and a binary variable was produced, which consisted of combined middle and lower tertile responses and upper tertile responses.

In the online survey, doctors were invited to complete the 12-Item General Health Questionnaire (GHQ-12), ${ }^{18}{ }^{19}$ which measures CMD symptoms. The comparison sample completed a paper version of the GHQ-12 prior to participation in the telephone interview study. Endorsing four or more symptoms represented the cut-off point for classification as a possible case of CMD.

Participants in both the military doctor and comparison samples answered questions about their mental health and related help-seeking within the last three years in three categories. Participants were asked if they had experienced (1) stress, emotional or mental health problems; (2) problems with alcohol; and (3) problems related to relationships or families. They were then asked if they had sought help for each of the problem categories. Interview study participants were asked if they had sought help from formal sources including mental health specialist, doctor, online and telephone therapy; doctors were asked if they had sought formal help for each of the problem categories.

\section{Analyses}

Analyses were undertaken using the statistical software package SPSS V.24. Descriptive statistics were generated for the various stigma measures, and categorical variables were explored using Pearson's $\chi^{2}$ tests. The associations between mental health-related stigmatisation, self-stigmatisation, helpseeking and probable CMD symptoms, and self-reported mental health, alcohol, family and relationship problems were examined using unadjusted logistic regression analyses to produce ORs with 95\% CIs. ORs were further adjusted for sex and service background. Similar analyses examined the association of stigmatisation, self-stigmatisation and probable CMD symptoms with help-seeking and mental health within the doctor sample only. For doctors, ORs were adjusted for rank, professional status, number of years of military service, service background, sex and clinical specialty. Statistical significance was defined as $\mathrm{P} \leq 0.05$.

\section{RESULTS}

\section{Sample description}

Of the 1154 military doctors eligible for inclusion in the survey, 678 participated (response rate 59\%). Two hundred and forty-two of 307 (79\%) Royal Navy doctors, 262 of 562 (47\%) Army doctors and 174 of 285 (61\%) Royal Air Force doctors took part. Of the military doctors, $35.7 \%$ were Royal Navy, 38.6\% Army and 25.7\% Royal Air Force. Of 1727 comparison sample individuals invited to participate in the telephone interview study, 1448 elected to take part (response rate 84.5\%).

Of the military doctors $63.4 \%$ were of junior or field officer rank and $36.6 \%$ were of staff officer (higher) rank or equivalent. There was an even distribution of unaccredited or training grade doctors $(49.9 \%)$ and accredited, consultant or general practitioner doctors $(50.1 \%) ; 30.5 \%$ worked in a primary care setting and $69.5 \%$ in secondary care. Various lengths of military service were adequately represented. Women constituted 
Table 1 Characteristics of military doctors, stigmatisation, attitudes to mental healthcare and mental health symptoms

\begin{tabular}{|c|c|c|c|c|c|c|}
\hline Doctor characteristics $(\mathrm{n}, \%)$ & $\begin{array}{l}\text { Reported 7-19 } \\
\text { stigmatisation } \\
\text { items, n (\%)† }\end{array}$ & AOR & $\begin{array}{l}\text { Reported 2-5 } \\
\text { self-stigmatisation } \\
\text { items, } \mathbf{n}(\%)\end{array}$ & AOR & $\begin{array}{l}\text { GHQ-12 } \\
\text { caseness, n (\%) }\end{array}$ & AOR \\
\hline \multicolumn{7}{|l|}{ Rank group } \\
\hline OF2-OF3 $(429,63.4)$ & $215(50.1)$ & 1 & $205(47.8)$ & 1 & $112(26.1)$ & 1 \\
\hline OF4 and above $(248,36.6)$ & $87(35.2)$ & $0.68(0.38-1.21)$ & $87(35.4)$ & $0.76(0.41-1.42)$ & $53(21.5)$ & $0.77(0.38-1.59)$ \\
\hline \multicolumn{7}{|l|}{ Professional status } \\
\hline $\begin{array}{l}\text { Unaccredited/training grade } \\
(337,49.9)\end{array}$ & $175(51.9)$ & 1 & $166(49.3)$ & 1 & $91(27.0)$ & 1 \\
\hline $\begin{array}{l}\text { Accredited consultant or GP (338, } \\
50.1 \text { ) }\end{array}$ & $127(37.7)$ & $0.78(0.46-1.33)$ & $125(37.2)$ & $0.82(0.47-1.43)$ & $73(21.7)$ & $0.65(0.34-1.25)$ \\
\hline \multicolumn{7}{|l|}{ Work area } \\
\hline Primary care $(205,30.5)$ & $91(44.6)$ & 1 & $89(43.6)$ & 1 & $51(25.0)$ & 1 \\
\hline Secondary care $(467,69.5)$ & $209(44.8)$ & $1.05(0.72-1.54)$ & $202(43.3)$ & $0.92(0.62-1.37)$ & $115(24.7)$ & $0.99(0.63-1.57)$ \\
\hline \multicolumn{7}{|l|}{ Service length } \\
\hline $0-5$ years $(109,16.1)$ & $53(48.6)$ & 1 & $45(42.3)$ & 1 & $20(18.3)$ & 1 \\
\hline $6-10$ years $(152,22.5)$ & $73(48.0)$ & $0.96(0.59-1.58)$ & $89(58.6)$ & $2.17(1.29-3.65)^{* *}$ & 45 (29.6) & $1.88(1.01-3.48)^{*}$ \\
\hline $11-15$ years $(184,27.2)$ & $88(47.8)$ & $0.98(0.61-1.58)$ & $76(41.3)$ & $1.24(0.74-2.08)$ & $55(29.9)$ & $2.27(1.22-4.22)$ \\
\hline $16-20$ years $(106,15.7)$ & $48(45.3)$ & $0.89(0.52-1.53)$ & $39(37.1)$ & $1.33(0.69-2.57)$ & $23(21.9)$ & $1.59(0.72-3.49)$ \\
\hline More than 20 years $(126,18.6)$ & $40(32.0)$ & $0.49(0.29-0.84)^{* *}$ & $43(34.4)$ & $1.38(0.67-2.82)$ & $23(18.4)$ & $1.35(0.58-3.18)$ \\
\hline \multicolumn{7}{|l|}{ Service background } \\
\hline Royal Navy $(242,35.7)$ & $135(55.8)$ & 1 & $120(50.4)$ & 1 & $68(28.1)$ & 1 \\
\hline Army $(262,38.6)$ & $98(37.5)$ & $0.46(0.31-0.68)^{* * *}$ & $93(35.8)$ & $0.55(0.37-0.81)^{* *}$ & $51(19.6)$ & $0.61(0.39-0.95)^{*}$ \\
\hline Royal Air Force $(174,25.7)$ & $70(40.2)$ & $0.51(0.34-0.77)^{\star *}$ & $78(44.8)$ & $0.75(0.50-1.14)$ & $47(27.0)$ & $0.93(0.59-1.47)$ \\
\hline \multicolumn{7}{|l|}{ Sex } \\
\hline Female $(189,27.8)$ & $90(47.9)$ & 1 & $93(49.7)$ & 1 & $54(28.9)$ & 1 \\
\hline Male $(489,72.2)$ & $213(43.6)$ & $0.84(0.59-1.20)$ & $200(41.0)$ & $0.75(0.52-1.08)$ & $112(23.0)$ & $0.80(0.53-1.20)$ \\
\hline
\end{tabular}

${ }^{*} \mathrm{P}<0.05,{ }^{* *} \mathrm{P}<0.01,{ }^{* * *} \mathrm{P}<0.001$.

tAttitudes to mental healthcare, perceived barriers to care and stigmatisation.

$\ddagger O R$ adjusted for rank, professional status, number of years served, service background, sex and clinical specialty.

AOR, adjusted OR; GHQ-12, 12-Item General Health Questionnaire; GP, general practitioner.

$27.8 \%$ of the military doctor sample (Table 1 ). Within the comparison group, 667 personnel (46.1\%) were serving on a regular military engagement, $124(8.6 \%)$ were serving on a reserve engagement and $657(45.4 \%)$ were ex-service (Table 2).

\section{Stigmatisation among military doctors}

Within the doctor sample, following adjustment for confounding variables, higher (upper tertile) levels of stigmatisation (endorsing 7-19 items) were significantly less frequent among those who had served for 20 years or more compared with those with shorter lengths of service $(32.5 \%$ vs between $45.3 \%$ and $48.6 \%)$. Stigmatisation was also significantly lower among Army (37.5\%) and Royal Air Force (40.2\%) doctors than among Royal Navy doctors (55.8\%). For all other doctor characteristics, stigmatisation levels were not significantly different. For self-stigmatisation, compared with those with less than five years of military service $(42.3 \%)$, only doctors who had served between six and ten years reported significantly more self-stigmatisation (58.6\%). Compared with Royal Navy doctors, Army doctors reported significantly lower levels of self-stigmatisation (35.8\% vs 50.4\%), while Royal Air Force doctors' self-stigmatisation levels were not statistically significantly different from Royal Navy doctors. Compared with doctors serving for less than five years $(18.3 \%)$, probable cases of CMD were significantly higher among doctors who had served between six and ten years $(29.6 \%$ caseness $)$ and $11-15$ years $(29.9 \%$ caseness) (Table 1$)$.
Mental health and help-seeking

All comparison sample members were recruited on the basis that they self-reported a stress, emotional or mental health problem occurring in the last threeyears; $46.1 \%$ of military doctors reported such a problem. Among those who had experienced such problems, doctors were significantly less likely than veterans to have sought help (35.6\% vs $59.8 \%)$ and were less likely to have sought help than both regulars (54.1\%) and reserves (58.1\%).

Doctors were significantly less likely than veterans to report an alcohol problem in the past three years $(3.3 \%$ vs $16.6 \%)$ and were less likely to report such a problem than both regulars (14.6\%) and reserves $(11.3 \%)$. In all four samples, participants reporting subjective alcohol problems sought help infrequently, ranging from $13.6 \%$ among doctors to $42.9 \%$ among reserves; failure to find significant differences in help-seeking was probably related to low help-seeking numbers, resulting in insufficient statistical power.

Doctors were significantly less likely than veterans to report relationship problems in the past three years $(31.9 \%$ vs $51.5 \%)$ and were less likely to report such a problem than both regulars (57.7\%) and reserves (55.3\%). Of those reporting such a problem, doctors were significantly less likely to seek help than veterans $(24.1 \%$ vs $36.3 \%)$ and were less likely to seek help than both regulars (43.8\%) and reserves (39.7\%).

Doctors were significantly less likely to be classified as having a probable CMD than veterans (24.6\% vs $48.8 \%$ ) and were less likely to self-report caseness than both regulars $(44.0 \%)$ and reserves (43.1\%) (Table 2). 
Table 2 Perceived problems, help-seeking and mental health disorder symptoms among military doctors, UK Armed Forces serving personnel and ex-service veterans

\begin{tabular}{|c|c|c|c|c|}
\hline Characteristics & No, $n(\%)$ & Yes, n (\%) & OR $(95 \% \mathrm{Cl})$ & AOR $(95 \% \mathrm{Cl}) \dagger$ \\
\hline \multicolumn{5}{|c|}{ Stress, emotional or mental health problem in the last three years } \\
\hline Ex-service $(n=657)$ & $0(0.0)$ & $657(100.0)$ & & \\
\hline Doctor $(n=673)$ & $363(53.9)$ & $310(46.1)$ & & \\
\hline Regular $(n=667)$ & $0(0.0)$ & $667(100.0)$ & & \\
\hline Reserve $(n=124)$ & $0(0.0)$ & $124(100.0)$ & & \\
\hline \multicolumn{5}{|c|}{ Sought help for a stress, emotional or mental health problem in the last three years§ } \\
\hline Ex-service $(n=657)$ & $264(40.2)$ & $393(59.8)$ & 1 & 1 \\
\hline Doctor $(n=309)$ & $199(64.4)$ & $110(35.6)$ & $0.37(0.28 \text { to } 0.49)^{* * *}$ & $0.32(0.24 \text { to } 0.43)^{* * *}$ \\
\hline Regular $(n=667)$ & $306(45.9)$ & $361(54.1)$ & $0.79(0.64 \text { to } 0.99)^{*}$ & $0.76(0.61 \text { to } 0.95)^{*}$ \\
\hline Reserve $(n=124)$ & $52(41.9)$ & $72(58.1)$ & $0.93(0.63$ to 1.37$)$ & $0.86(0.58$ to 1.27$)$ \\
\hline \multicolumn{5}{|c|}{ Alcohol problem in the last three years } \\
\hline Ex-service $(n=657)$ & $548(83.4)$ & $109(16.6)$ & 1 & 1 \\
\hline Doctor $(n=667)$ & $645(96.7)$ & $22(3.3)$ & $0.17(0.12 \text { to } 0.28)^{* * *}$ & $0.19(0.12$ to 0.30$)$ \\
\hline Regular $(n=665)$ & $568(85.4)$ & $97(14.6)$ & $0.86(0.64$ to 1.16$)$ & $0.89(0.66$ to 1.20$)$ \\
\hline Reserve $(n=124)$ & $110(88.7)$ & $14(11.3)$ & $0.64(0.35$ to 1.16$)$ & $0.70(0.39$ to 1.28$)$ \\
\hline \multicolumn{5}{|c|}{ Sought help for an alcohol problem in the last three years§ } \\
\hline Ex-service $(n=109)$ & $83(76.1)$ & $26(23.9)$ & 1 & 1 \\
\hline Doctor $(n=22)$ & $19(86.4)$ & $3(13.6)$ & $0.50(0.14$ to 1.84$)$ & $0.54(0.15$ to 1.99$)$ \\
\hline Regular $(n=97)$ & $68(70.1)$ & $29(29.9)$ & $1.36(0.73$ to 2.53$)$ & $1.34(0.72$ to 2.49$)$ \\
\hline Reserve $(n=14)$ & $8(57.1)$ & $6(42.9)$ & $2.39(0.76$ to 7.54$)$ & $2.40(0.75$ to 7.60$)$ \\
\hline \multicolumn{5}{|c|}{ Relationship or family problem in the last threeyears } \\
\hline Ex-service $(n=653)$ & $317(48.5)$ & $336(51.5)$ & 1 & 1 \\
\hline Doctor $(n=665)$ & $457(68.1)$ & $214(31.9)$ & $0.44(0.35 \text { to } 0.55)^{* * *}$ & $0.46(0.37 \text { to } 0.58)^{* * *}$ \\
\hline Regular $(n=665)$ & $281(42.3)$ & $384(57.7)$ & $1.29(1.04 \text { to } 1.60)^{*}$ & $1.31(1.05 \text { to } 1.63)^{*}$ \\
\hline Reserve $(n=123)$ & $55(44.7)$ & $68(55.3)$ & $1.17(0.79$ to 1.72$)$ & $1.22(0.83$ to 1.80$)$ \\
\hline \multicolumn{5}{|c|}{ Sought help for a relationship or family problem in the last three years§ } \\
\hline Ex-service $(n=336)$ & $214(63.7)$ & $122(36.3)$ & 1 & 1 \\
\hline Doctor $(n=212)$ & $161(75.9)$ & $51(24.1)$ & $0.56(0.38 \text { to } 0.82)^{* *}$ & $0.54(0.36 \text { to } 0.80)^{* *}$ \\
\hline Regular $(\mathrm{n}=384)$ & $216(56.3)$ & $168(43.8)$ & $1.36(1.01 \text { to } 1.84)^{*}$ & 1.34 (0.99 to 1.81$)$ \\
\hline Reserve $(n=68)$ & $41(60.3)$ & $27(39.7)$ & 1.16 (0.68 to 1.97$)$ & $1.15(0.67$ to 1.96$)$ \\
\hline \multicolumn{5}{|c|}{ GHQ-12 four or more symptoms } \\
\hline Ex-service $(n=656)$ & $336(51.2)$ & $320(48.8)$ & 1 & 1 \\
\hline Doctor $(n=676)$ & $510(74.5)$ & $166(24.6)$ & $0.34(0.27 \text { to } 0.43)^{* * *}$ & $0.34(0.27$ to 0.43$)$ \\
\hline Regular $(\mathrm{n}=667)$ & $373(56.0)$ & $293(44.0)$ & 0.83 (0.66 to 1.02$)$ & $0.82(0.66$ to 1.02$)$ \\
\hline Reserve $(n=123)$ & $70(56.9)$ & $53(43.1)$ & 0.80 (0.54 to 1.17$)$ & 0.78 (0.53 to 1.16$)$ \\
\hline
\end{tabular}

${ }^{*} \mathrm{P}<0.05,{ }^{*} \mathrm{P}<0.01,{ }^{* * *} \mathrm{P}<0.001$

†Adjusted for sex and service background (Royal Navy, Army, Royal Air Force).

¥All groups except doctors were sampled on the basis that they reported a stress emotional problem in the last three years.

$\S$ This is the proportion of those who endorsed having a problem in the last three years.

AOR, adjusted OR; GHQ-12, 12-Item General Health Questionnaire.

\section{Stigmatisation across samples}

Doctors were more likely to endorse each of the eight stigmatisation items than regulars, reserves and veterans. The most common stigmatisation items were not wanting a mental health problem to appear on medical records, unit leaders treating a person with mental health problems differently, and unit members or colleagues having less confidence in a person if they were known to have mental health problems. Six of the seven stigmatisation items were endorsed by around half of the doctors. All practical barriers to care were endorsed at a higher level by doctors than by the comparison samples; among doctors, the most commonly reported barrier was difficulty getting time off work for an appointment. With the exception of the item ' $I$ want to solve the problem on my own', which was endorsed by $59.6 \%$ of the doctors and around $53.0 \%$ of the other groups, negative attitudes towards and a desire to self-manage mental health problems were reported at much lower levels than either stigmatisation, self-stigmatisation or practical barriers to care. Doctors were more likely than the three reference groups to endorse self-stigma. The two most commonly endorsed items were feeling inadequate for seeking mental healthcare and feeling worse about oneself if unable to solve one's own problems; these were endorsed by $65.5 \%$ and $51.3 \%$ of the doctors, respectively (Table 3 ).

\section{Self-stigmatisation and mental health}

Compared with veterans, military doctors were significantly more likely to report both stigmatisation and perceived barriers to care and self-stigmatisation irrespective of whether they were cases on the GHQ-12 or not. Although all subgroups reported more stigmatisation, perceived barriers to care and self-stigmatisation when they were classified as cases on the GHQ-12, doctors showed the largest increases compared with the other 
Table 3 Mental health-related stigmatisation, attitudes to mental healthcare, perceived barriers and self-stigmatisation

\begin{tabular}{|c|c|c|c|c|c|c|}
\hline \multirow[b]{2}{*}{ Domain } & \multirow[b]{2}{*}{ Stigma item } & \multicolumn{4}{|l|}{ Endorsed scale item } & \multirow[b]{2}{*}{$\mathbf{P}$} \\
\hline & & Doctor $(n=678) n(\%)$ & Regular $(n=667) n(\%)$ & Reserve $(n=124) n(\%)$ & Ex-service $(n=657) n(\%)$ & \\
\hline Sti & $\begin{array}{l}\text { Not wanting a mental health problem to be } \\
\text { on my medical records. }\end{array}$ & $455(67.3)$ & $301(45.1)$ & $64(51.6)$ & $250(38.1)$ & $<0.001$ \\
\hline Sti & $\begin{array}{l}\text { My unit leaders/bosses might treat me } \\
\text { differently. }\end{array}$ & $438(64.8)$ & $303(45.5)$ & $54(43.5)$ & $255(38.8)$ & $<0.001$ \\
\hline Sti & $\begin{array}{l}\text { Members of my unit or my colleagues might } \\
\text { have less confidence in me. }\end{array}$ & $414(61.3)$ & $287(43.0)$ & $52(41.9)$ & $205(31.2)$ & $<0.001$ \\
\hline Sti & It would be too embarrassing. & $326(48.3)$ & $232(34.8)$ & $46(37.1)$ & $167(25.4)$ & $<0.001$ \\
\hline Sti & $\begin{array}{l}\text { I would be seen as weak (by those who are } \\
\text { important to me). }\end{array}$ & $318(47.0)$ & $248(37.2)$ & $46(37.1)$ & $203(30.9)$ & $<0.001$ \\
\hline Sti & $\begin{array}{l}\text { Concern about what my friends or family } \\
\text { might think. }\end{array}$ & $263(38.9)$ & $200(30.0)$ & $42(33.9)$ & $181(27.5)$ & $<0.001$ \\
\hline Sti & $\begin{array}{l}\text { My leaders/bosses would blame me for the } \\
\text { problem. }\end{array}$ & $138(20.4)$ & $96(14.4)$ & $23(18.5)$ & $81(12.3)$ & $<0.001$ \\
\hline PB & It is difficult to get an appointment. & $109(16.1)$ & $41(6.1)$ & $18(14.5)$ & $104(12.8)$ & $<0.001$ \\
\hline PB & I don't have adequate transport. & $17(2.5)$ & $5(0.7)$ & $1(0.8)$ & $6(0.9)$ & $<0.05$ \\
\hline Att & Wanting to solve the problem on my own. & $401(59.6)$ & $356(53.4)$ & $66(53.2)$ & $347(52.8)$ & 0.05 \\
\hline Att & My visit would not remain confidential. & $160(23.7)$ & $60(9.0)$ & $21(16.9)$ & $54(8.2)$ & $<0.001$ \\
\hline Att & $\begin{array}{l}\text { Mental health treatment has harmful side } \\
\text { effects. }\end{array}$ & $48(7.1)$ & $33(4.9)$ & $10(8.1)$ & $50(7.6)$ & 0.20 \\
\hline Att & $\begin{array}{l}\text { I would think less of a team member if I } \\
\text { knew he/she was receiving mental health } \\
\text { counselling. }\end{array}$ & $44(6.5)$ & $44(6.6)$ & $5(4.0)$ & $34(5.2)$ & 0.50 \\
\hline Att & $\begin{array}{l}\text { I have had previous bad experiences with } \\
\text { mental health professionals. }\end{array}$ & $29(4.3)$ & $54(8.1)$ & $14(11.3)$ & $90(13.7)$ & $<0.001$ \\
\hline Self & $\begin{array}{l}\text { I would be less satisfied with myself if I went } \\
\text { to a mental health professional. }\end{array}$ & $260(38.5)$ & $165(24.7)$ & $32(25.8)$ & $156(23.7)$ & $<0.001$ \\
\hline Self & $\begin{array}{l}\text { It would make me feel inferior to ask a mental } \\
\text { health professional for help. }\end{array}$ & $149(22.1)$ & $126(18.9)$ & $26(21.0)$ & $112(17.0)$ & 0.13 \\
\hline Self & $\begin{array}{l}\text { Seeking psychological help would make me } \\
\text { feel less intelligent. }\end{array}$ & $69(10.2)$ & $62(9.3)$ & $14(11.3)$ & $54(8.2)$ & 0.54 \\
\hline
\end{tabular}

$P$ values are for Pearson's $\chi^{2}$ test.

Att, attitudes to mental healthcare; PB, perceived barriers to care; Self, self-stigmatisation; Sti, stigmatisation.

three subgroups. Subgroup analyses suggested that seeking help was associated with a reduction in self-stigmatisation in all groups and was significantly lower among help-seekers in the veteran and regular subgroups (Table 4).

\section{DISCUSSION}

To the best of our knowledge, this cross-sectional study of mental health, related attitudes and help-seeking is the first to be conducted among military doctors serving in the UK Armed Forces. The main findings of this study were that military doctors reported fewer symptoms of CMD than other military subgroups; $24.6 \%$ of military doctors reported symptoms of CMD compared with between $43 \%$ and $40 \%$ of the other military subgroups. For comparison, in a literature review published in 2015, Vijendren et $a l^{20}$ reported that $32 \%$ of hospital consultants and $28 \%$ of oncologists had mental health problems, 44\% of accident and emergency consultants reported psychological distress, $32 \%$ of colorectal and vascular surgeons experienced job-related exhaustion, and $27 \%$ of radiologists and gastroenterologist experienced psychiatric morbidity. Although such comparisons are crude, it seems that military doctors may have marginally better mental health than their civilian counterparts.

Within the military doctor group, stigmatisation, negative attitudes to mental healthcare and a desire to self-manage and self-stigmatisation were higher than the comparison groups irrespective of being classified as a CMD case on the GHQ-12 or not. There was a general trend towards reporting more stigma in the presence of caseness across the subgroups, which was highly significant among military doctors. For military doctors, this outcome is consistent with the findings from previous military 
Table 4 Service background or profession, mental health, and self-stigma

\begin{tabular}{|c|c|c|c|c|c|}
\hline Mental health & Subsample & \multicolumn{2}{|c|}{ Upper tertile, n (\%) } & OR $(95 \% \mathrm{Cl})$ & AOR $(95 \% \mathrm{Cl}) \dagger$ \\
\hline \multicolumn{6}{|c|}{ Stigma, attitudes and barriers to care } \\
\hline \multirow[t]{4}{*}{ Not a GHQ case } & Ex-service (336) & $62(18.5)$ & & 1 & 1 \\
\hline & Doctor $(510)$ & $199(39.0)$ & & $2.83(2.04 \text { to } 3.93)^{* * *}$ & $2.61(1.87 \text { to } 3.64)^{* * *}$ \\
\hline & Regular P3 (373) & $87(23.3)$ & & $1.34(0.93$ to 1.94$)$ & $1.35(0.94$ to 1.95$)$ \\
\hline & Reserve P3 (70) & $18(25.7)$ & & $1.53(0.84$ to 2.80$)$ & $1.36(0.74$ to 2.50$)$ \\
\hline \multirow[t]{2}{*}{ GHQ case } & Ex-service (320) & $95(29.7)$ & & 1 & 1 \\
\hline & Reserve P3 (53) & $24(45.3)$ & & $1.96(1.09 \text { to } 3.54)^{*}$ & $1.93(1.07 \text { to } 3.50)^{*}$ \\
\hline \multicolumn{6}{|l|}{ Self-stigma } \\
\hline \multirow[t]{3}{*}{ Not a GHQ case } & Ex-service (336) & $92(27.4)$ & & 1 & 1 \\
\hline & Doctor $(510)$ & $193(37.8)$ & & $1.62(1.20 \text { to } 2.18)^{* * *}$ & $1.55(1.14 \text { to } 2.10)^{* *}$ \\
\hline & Regular P3 (373) & $112(30.0)$ & & $1.14(0.82$ to 1.58$)$ & $1.15(0.83$ to 1.58$)$ \\
\hline GHQ case & Reserve P3 (53) & $22(41.5)$ & & $1.30(0.72$ to 2.35$)$ & $1.30(0.72$ to 2.35$)$ \\
\hline \multicolumn{6}{|c|}{ Help-seeking and self-stigmatisation } \\
\hline \multicolumn{2}{|c|}{ Subsample } & No help & Help & OR $(95 \% \mathrm{Cl})$ & AOR $(95 \% \mathrm{Cl}) \dagger$ \\
\hline \multicolumn{2}{|c|}{ Ex-service (657) (no help $n=264$, help $n=393$ ) } & $111(42.0)$ & $94(23.9)$ & $0.43(0.31 \text { to } 0.61)^{* * *}$ & $0.43(0.30$ to 0.60$)$ \\
\hline \multicolumn{2}{|c|}{ Doctor (674) (no help $n=562$, help $n=112$ ) } & $250(44.5)$ & $43(38.4)$ & $0.78(0.51$ to 1.18$)$ & $0.73(0.48$ to 1.11$)$ \\
\hline \multicolumn{2}{|c|}{ Regular P3 (667) (no help $n=306$, help $n=361$ ) } & $136(44.4)$ & $92(25.5)$ & $0.43(0.31 \text { to } 0.60)^{* * *}$ & $0.41(0.30 \text { to } 0.58)^{* * *}$ \\
\hline \multicolumn{2}{|c|}{ Reserve P3 (124) (no help $n=52$, help $n=72$ ) } & $19(36.5)$ & $19(26.4)$ & $0.62(0.29$ to 1.35$)$ & $0.64(0.29$ to 1.43$)$ \\
\hline
\end{tabular}

${ }^{*} \mathrm{P}<0.05,{ }^{*} \mathrm{P}<0.01,{ }^{*}{ }^{*} \mathrm{P}<0.001$.

†Adjusted for sex and service background (Royal Navy, Army, Royal Air Force).

AOR, adjusted OR; GHQ, General Health Questionnaire.

research conducted byJones et al, (2015), indicating that there is a positive association between increasing mental distress and expressing greater levels of stigmatising beliefs. Our data further suggest that military doctors reporting a relationship, alcohol or mental health problem occurring in the last three years were significantly and substantially less likely to seek help than the comparison groups. In all subgroups, seeking help was associated with reduced stigma, and in the case of military doctors and regulars this was highly significant.

Our findings suggest that there may well be an important facet of mental health in military doctors that differs significantly from other military groups, namely the marked association between mental health stigmatisation and poorer mental health and a lower propensity to seek care. In keeping with the findings of Chew-Graham et al, where medical students reported self-stigmatising beliefs about the impact of mental difficulties on their career, military doctors were concerned about mental health problems appearing on their medical records, being treated differently and colleagues having less confidence in them. This does not seem to be unique to military doctors and may represent an aspect of medical culture. Our data lend support to the concept that individuals are often most concerned about how their mental health might be perceived by others. ${ }^{21} \mathrm{~A}$ recent systematic review suggests that stigmatisation can have a small to moderate negative effect on help-seeking behaviours. ${ }^{22}$ We found that stigmatisation was greater among those who had not engaged with mental healthcare and that it was markedly lower among those who had engaged in care. This is potentially important as it implies that negative views of mental healthcare are often revised after care is sought and are therefore potentially modifiable in the prodromal space.
The UK Armed Forces provide a comprehensive, occupationally focused mental healthcare service; among its objectives is to optimise mental health in order to maximise the number of personnel fit for deployed military duties. ${ }^{23-25}$ Despite having ready access to such care, previous studies suggest that military personnel may not necessarily choose to access it when required. In the case of military doctors, this may well be compounded by a particular unwillingness to seek help when unwell; this outcome has been demonstrated in research among civilian doctors. ${ }^{26}$ Military doctors may therefore face both unique role-related and ubiquitous perceived or actual barriers to mental healthcare, which may impact the likelihood of seeking care through standard military routes. Within the civilian sector, attempts to overcome this challenge have included the provision of separate and confidential services for medical personnel. Garelick ${ }^{27}$ suggests that self-referral to a confidential psychological service with easy access to a face-to-face consultation may make it easier to overcome barriers to care. Additionally, other care pathway entry points such as online or remotely delivered therapies, which have been shown to be effective for some mental health problems such as depression and obsessive compulsive disorder, might further promote access to care. ${ }^{28-30}$ Within the UK Armed Forces, self-referral to mental health services appeared to facilitate help-seeking and had no adverse impact on the capacity of care providers. ${ }^{31}$ Exploring novel, multimodal ways of facilitating access to care which are perceived as tailored towards the unique needs of military doctors might have a positive impact on their help-seeking behaviours. If alternative means of mental health support for military healthcare professionals were to be provided, it might be helpful to develop this in collaboration with potential service users, the aim being to ensure that the 
service is tailored to meet the needs of those people for whom it is being provided.

Given that the current study is military doctor-specific, further studies of military healthcare specialists could be expanded to include other professional groups such as military nurses and allied health professionals as they may be similarly adversely impacted by barriers to care. Military medical personnel other than doctors do not automatically hold officer status, which is known to buffer mental distress in the Armed Forces ${ }^{32}$; if they are similarly affected by stigma, they may not benefit from higher rank as a protective factor.

\section{Strengths and limitations}

Our data are cross sectional and limit our ability to infer causation $^{33}$; however, we used psychometrically sound survey instruments that have previously been used in a diverse range of UK military groups. This enabled comparisons to be made with a large cohort of non-medical personnel and helped us to identify unique differences related to the military medical role. What is not clear is whether the findings are unique to military doctors or whether they are relevant to all military healthcare professionals. A further limitation to this study is the use of an internet-based survey. Whereas using face-to-face interviews can result in response rates of $80 \%$ or more, internet or postal surveys can produce lower response rates. ${ }^{34}$ This study achieved a response rate of $59 \%$ in the online survey of doctors and $85 \%$ in the comparison group telephone interviews, both of which, we argue are respectable but being markedly different in proportion, may have introduced some unmeasured bias. There were differences in the response rate of doctors from different branches of the military. The Army sample had a lower response rate than the other service branches, and it is possible that this may have introduced further bias. It may be that non-responders had worse mental health and greater self-stigmatising beliefs than those who participated, and this may have been a problem in the Army doctor sample in particular; we simply do not know.

\section{CONCLUSION}

Self-stigmatising beliefs about accessing help for mental health difficulties are common among military personnel especially when they are symptomatic and contemplating engaging with care. There was some evidence in this study that engagement with care may well positively impact stigmatisation and attitudes to mental healthcare. Military doctors reported lower levels of mental disorder symptoms than other military groups but higher levels of self-stigmatising beliefs. Most notably, military doctors were concerned about the possible negative impact of a mental disorder diagnosis being recorded in their medical records and how this might be negatively perceived by their peers. This is a potential barrier to accessing care that could potentially be overcome by promoting easier access to a tailored, confidential service possibly delivered remotely. This would need to be further evaluated for its utility. Finally, we do not know if stigma and reduced help-seeking is unique to military doctors; therefore, widening the study to all include a broad range of healthcare professionals might be helpful.

Collaborators Norman Jones, Dean Whybrow, Rikus Coetzee.

Contributors $\mathrm{RC}$ contributed to research design, commented extensively on the paper and collected the data. DW contributed to research design and commented extensively on the paper. NJ contributed to research design, performed the analyses and wrote the paper.
Funding This research received no specific grant from any funding agency in the public, commercial or not-for-profit sectors.

Competing interests None declared.

Patient consent Not required.

Ethics approval Ethical approval was granted by the UK Ministry of Defence Research Ethics Committee (535/MODREC/14 for the telephone interview study and 557/MODREC/14 for the doctor's study).

Provenance and peer review Not commissioned; externally peer reviewed.

(C) Article author(s) (or their employer(s) unless otherwise stated in the text of the article) 2018. All rights reserved. No commercial use is permitted unless otherwise expressly granted.

\section{REFERENCES}

1 Adams EFM, Lee AJ, Pritchard CW, et al. What stops us from healing the healers: a survey of help-seeking behaviour, stigmatisation and depression within the medical profession. Int J Soc Psychiatry 2010;56:359-70.

2 Vogt D. Mental health-related beliefs as a barrier to service use for military personnel and veterans: a review. Psychiatr Serv 2011;62:135-42.

3 Gould M, Adler A, Zamorski M, et al. Do stigma and other perceived barriers to mental health care differ across Armed Forces? J R Soc Med 2010;103:148-56.

4 Britt TW, Greene-Shortridge TM, Brink S, et al. Perceived stigma and barriers to care for psychological treatment: Implications for reactions to stressors in different contexts. J Soc Clin Psychol 2008;27:317-35.

5 Nash WP, Silva C, Litz B. The historic origins of military and veteran mental health stigma and the stress injury model as a means to reduce it. Psychiatr Ann 2009;39:789-94

6 Forbes HJ, Boyd CF, Jones N, et al. Attitudes to mental illness in the U.K. military: a comparison with the general population. Mil Med 2013:178:957-65.

7 Henderson M, Brooks SK, Del Busso L, et al. Shame! Self-stigmatisation as an obstacle to sick doctors returning to work: a qualitative study. BMJ Open 2012;2:e001776.

8 Chew-Graham CA, Rogers A, Yassin N. 'I wouldn't want it on my CV or their records': medical students' experiences of help-seeking for mental health problems. Med Educ 2003;37:873-80.

9 Wallace JE. Mental health and stigma in the medical profession. Health 2012;16:3-18

10 Adams EF, Lee AJ, Pritchard CW, et al. What stops us from healing the healers: a survey of help-seeking behaviour, stigmatisation and depression within the medical profession. Int J Soc Psychiatry 2010;56:359-70.

11 Davidson SK, Schattner PL. Doctors' health-seeking behaviour: a questionnaire survey. Med J Aust 2003;179:302-5.

12 Hotopf M, Hull L, Fear NT, et al. The health of UK military personnel who deployed to the 2003 Iraq war: a cohort study. Lancet 2006;367:1731-41.

13 Fear NT, Jones M, Murphy D, et al. What are the consequences of deployment to Iraq and Afghanistan on the mental health of the UK armed forces? A cohort study. Lancet 2010;375:1783-97.

14 Sharp ML, Fear NT, Rona RJ, et al. Stigma as a barrier to seeking health care among military personnel with mental health problems. Epidemiol Rev 2015;37:144-62.

15 Hoge CW, Castro CA, Messer SC, et al. Combat duty in Iraq and Afghanistan, mental health problems, and barriers to care. N Engl J Med 2004;351:13-22.

16 Clement S, Brohan E, Jeffery D, et al. Development and psychometric properties the Barriers to Access to Care Evaluation scale (BACE) related to people with mental ill health. BMC Psychiatry 2012;12:36

17 Vogel DL, Armstrong PI, Tsai PC, et al. Cross-cultural validity of the Self-Stigma of Seeking Help (SSOSH) scale: examination across six nations. J Couns Psychol 2013;60:303-10

18 Golderberg D. Williams P. A user's guide to the general health questionnaire. Windsor, UK: NFER-Nelson, 1988.

19 Goldberg DP, Gater R, Sartorius N, et al. The validity of two versions of the GHQ in the WHO study of mental illness in general health care. Psychol Med 1997;27:191-7.

20 Vijendren A, Yung M, Sanchez J. Occupational health issues amongst UK doctors: a literature review. Occup Med 2015;65:519-28.

21 Ben-Zeev D, Corrigan PW, Britt TW, et al. Stigma of mental illness and service use in the military. J Ment Health 2012;21:264-73.

22 Clement S, Schauman O, Graham T, et al. What is the impact of mental health-related stigma on help-seeking? A systematic review of quantitative and qualitative studies. Psychol Med 2015;45:11-27.

23 Whybrow D. Behavioural activation for the treatment of depression in military personnel. J R Army Med Corps 2013;159:15-20.

24 Whybrow D. Psychiatric nursing liaison in a combat zone: an autoethnography. J Psychiatr Ment Health Nurs 2013;20:896-901.

25 Whybrow D, Jones N, Greenberg N. Promoting organizational well-being: a comprehensive review of Trauma Risk Management. Occup Med 2015;65:331-6. 
26 Stanton J, Randal P. Doctors accessing mental-health services: an exploratory study. BMJ Open 2011;1:e000017.

27 Garelick Al. Doctors' health: stigma and the professional discomfort in seeking help. Psychiatrist 2012;36:81-4.

28 Kessler D, Lewis G, Kaur S, et al. Therapist-delivered Internet psychotherapy for depression in primary care: a randomised controlled trial. Lancet 2009;374:628-34.

29 Cuijpers P, Marks IM, van Straten A, et al. Computer-aided psychotherapy for anxiety disorders: a meta-analytic review. Cogn Behav Ther 2009;38:66-82.
30 Wootton BM. Remote cognitive-behavior therapy for obsessive-compulsive symptoms: A meta-analysis. Clin Psychol Rev 2016;43:103-13.

31 Kennedy I, Whybrow D, Jones N, et al. A service evaluation of self-referral to military mental health teams. Occup Med 2016:66:394-8.

32 Fear NT, Rubin GJ, Hatch S, et al. Job strain, rank, and mental health in the UK Armed Forces. Int J Occup Environ Health 2009:15:291-8.

33. Bryman A. Social research methods: Oxford university press, 2015.

34 Polit DF, Beck CT. Nursing research: generating and assessing evidence for nursing practice: Lippincott Williams \& Wilkins, 2008. 